2015

\title{
Preparing Students for the Advanced Manufacturing Environment Through Robotics, Mechatronics, and Automation Training
}

\author{
Ana M. Djuric \\ Wayne State University \\ Vukica Jovanovic \\ Old Dominion University, v2jovano@odu.edu \\ Tatiana V. Goris \\ Purdue University
}

Follow this and additional works at: https://digitalcommons.odu.edu/engtech_fac_pubs

Part of the Engineering Education Commons, and the Robotics Commons

\section{Repository Citation}

Djuric, Ana M.; Jovanovic, Vukica; and Goris, Tatiana V., "Preparing Students for the Advanced Manufacturing Environment Through Robotics, Mechatronics, and Automation Training" (2015). Engineering Technology Faculty Publications. 87.

https://digitalcommons.odu.edu/engtech_fac_pubs/87

\section{Original Publication Citation}

Djuric, A. M., Jovanovic, V. M., \& Goris, T. V. (2015). Preparing students for the advanced manufacturing environment through robotics, mechatronics and automation training. Paper presented at the 2015 ASEE Annual Conference and Exposition, Seattle, WA.

This Conference Paper is brought to you for free and open access by the Engineering Technology at ODU Digital Commons. It has been accepted for inclusion in Engineering Technology Faculty Publications by an authorized administrator of ODU Digital Commons. For more information, please contact digitalcommons@odu.edu. 


\section{Preparing Students for the Advanced Manufacturing Environment through Robotics, Mechatronics and Automation Training}

\section{Dr. Ana M. Djuric, Wayne State University}

Dr. Ana Djuric received Dipl.-Ing. degree in mechanical engineering from the University of Belgrade, Serbia, focusing in Control Systems, the M.A.Sc. degree in Industrial and Manufacturing Systems Engineering from University of Windsor, Canada in the area of Industrial Robotics, and a Ph.D. degree in Mechanical Engineering from University of Windsor, Canada in the area of Reconfigurable Robotics. Prior to her arrival at WSU, Dr. Djuric worked in the industry for 5 years. She worked as a machine and tool designer first and then as a Robotics software Analyst. Dr. Djuric worked as an Instructor for 4 years at the Mechanical, Automotive and Materials Engineering, and Industrial and Manufacturing and Systems Engineering departments at the University of Windsor. Since Fall 2011 she is an Assistant Professor of Engineering Technology in the College of Engineering at Wayne State University. Dr. Djuric is working on undergraduate and graduate research and she is a member of Council on Undergraduate Research (CUR). Dr. Djuric research areas are Industrial robots, kinematics, dynamics, control, and advanced manufacturing systems. She published over 30 journal and conference papers.

\section{Dr. Vukica M. Jovanovic, Old Dominion University}

Dr. Jovanovic received her dipl.ing and M.Sc. in Industrial Engineering from University of Novi Sad, Serbia. She received a $\mathrm{PhD}$ in Technology at Purdue University, while working as a $\mathrm{PhD}$ student in Center for Advanced Manufacturing, Product Lifecycle Management Center of Excellence. Dr. Jovanovic is currently serving as Assistant Professor of Engineering Technology, Frank Batten College of Engineering and Technology at ODU. She is teaching classes in the area of mechatronics and computer aided engineering. Her research Interests are: mechatronics, robotics, digital manufacturing, product lifecycle management, manufacturing systems, ergonomics, human factors, assembly, disassembly, reverse engineering, RFID, and engineering education.

\section{Dr. Tatiana V. Goris, Purdue University, West Lafayette}

Dr. Tatiana Goris (tgoris@ @urdue.edu) is a Clinical Assistant Professor at Purdue University (College of Technology at Columbus, IN). She teaches various undergraduate courses in Mechanical Engineering Technology. In 2012 Dr. Goris received her PhD in Technology from Purdue University, IN. She also held MS degree (1999) in Electronics Engineering from Taganrog Institute of Technology, Russia. 


\title{
Preparing Students for the Advanced Manufacturing Environment through
}

\author{
Robotics, Mechatronics and Automation Training
}

\begin{abstract}
:
Automation is one of the key areas for modern manufacturing systems. It requires coordination of different machines to support manufacturing operations in a company. Recent studies show that there is a gap in the STEM workforce preparation in regards to highly automated production environments. Industrial robots have become an essential part of these semi-automated and automated manufacturing systems. Their control and programming requires adequate education and training in robotics theory and applications. Various engineering technology departments offer different courses related to the application of robotics. These courses are a great way to inspire students to learn about science, math, engineering, and technology while providing them with workforce skills. However, some challenges are present in the delivery of such courses. One of these challenges includes the enrollment of students who come from different engineering departments and backgrounds. Such a multidisciplinary group of students can pose a challenge for the instructor to successfully develop the courses and match the content to different learning styles and math levels. To overcome that challenge, and to spark students' interest, the certified education robot training can greatly support the teaching of basic and advanced topics in robotics, kinematics, dynamics, control, modeling, design, CAD/CAM, vision, manufacturing systems, simulation, automation, and mechatronics. This paper will explain how effective this course can be in unifying different engineering disciplines when using problem solving related to various important manufacturing automaton problems. These courses are focused on educational innovations related to the development of student competency in the use of equipment and tools common to the discipline, and associated curriculum development at three public institutions, in three different departments of mechanical engineering technology. Through these courses students make connections between the theory and real industrial applications. This aspect is especially important for tactile or kinesthetic learners who learn through experiencing and doing things. They apply real mathematical models and understand physical implications through labs on industrial grade robotic equipment and mobile robots.
\end{abstract}

\section{Introduction}

Based on a study conducted by the market research firm, Metra Martech, "Positive Impact of Industrial Robots on Employment," which was published in Tokyo 2011, the following conclusion was presented: "One million industrial robots currently in operation have been directly responsible for the creation of close to three million jobs, the study concluded. A growth in robotics use over the next five years will result in the creation of one million high quality jobs around the world. Robots will help to create jobs in some of the most critical industries of this century: consumer electronics, food, solar \& wind power, and advanced battery manufacturing to name just a few." ${ }^{1}$ Educational efforts presented in this paper are closely tied to the latest trends specified in "Investing in Next-Generation Robotics" platform by President Obama (June 24, 2011) ${ }^{2}$. The President has launched the Advanced Manufacturing Partnership (AMP), a national effort bringing together industry, universities, and the federal government to invest in the emerging technologies that will create high quality manufacturing jobs and enhance our global competitiveness. One of the key steps being taken by the federal government is investing in 
Next-Generation Robotics. Hence, universities across the country need to update their training efforts in next generation robotics to meet the needs for the $21^{\text {st }}$ century manufacturing workforce. This will be done by adding the necessary curriculum modules, which will integrate practices related to the mobility, flexibility, reconfigurability, and intelligence components of manufacturing systems.

Different multidisciplinary subjects, such as robotics, mechatronics, and automation are highly important and are taught at many national and international universities. ${ }^{3-13}$ Most of them have modern labs and equipment, which students used for their senior and capstone projects. The significance of the multidisciplinary subjects can be underscored by the fact that there are already many eminent journals: the International Journal of Robotic research, the Journal of Intelligent \& Robotic Systems, the Journal of Mechanisms and Robotics, the International Journal of Advanced Robotic Systems, the Journal of Robotic and Mechatronics, the Journal of Mechatronics and Intelligent Manufacturing, Mechatronics-The Science of Intelligent Machines, Mechatronics - An International Journal, the International Journal of Robotics and Automation, The Open Automation and Control Systems Journal, and the International Journal of Automation and Computing. Academic institutions in the United States have also been responding to the changes in the industry by developing new multi and interdisciplinary courses and curricula on the listed topics.

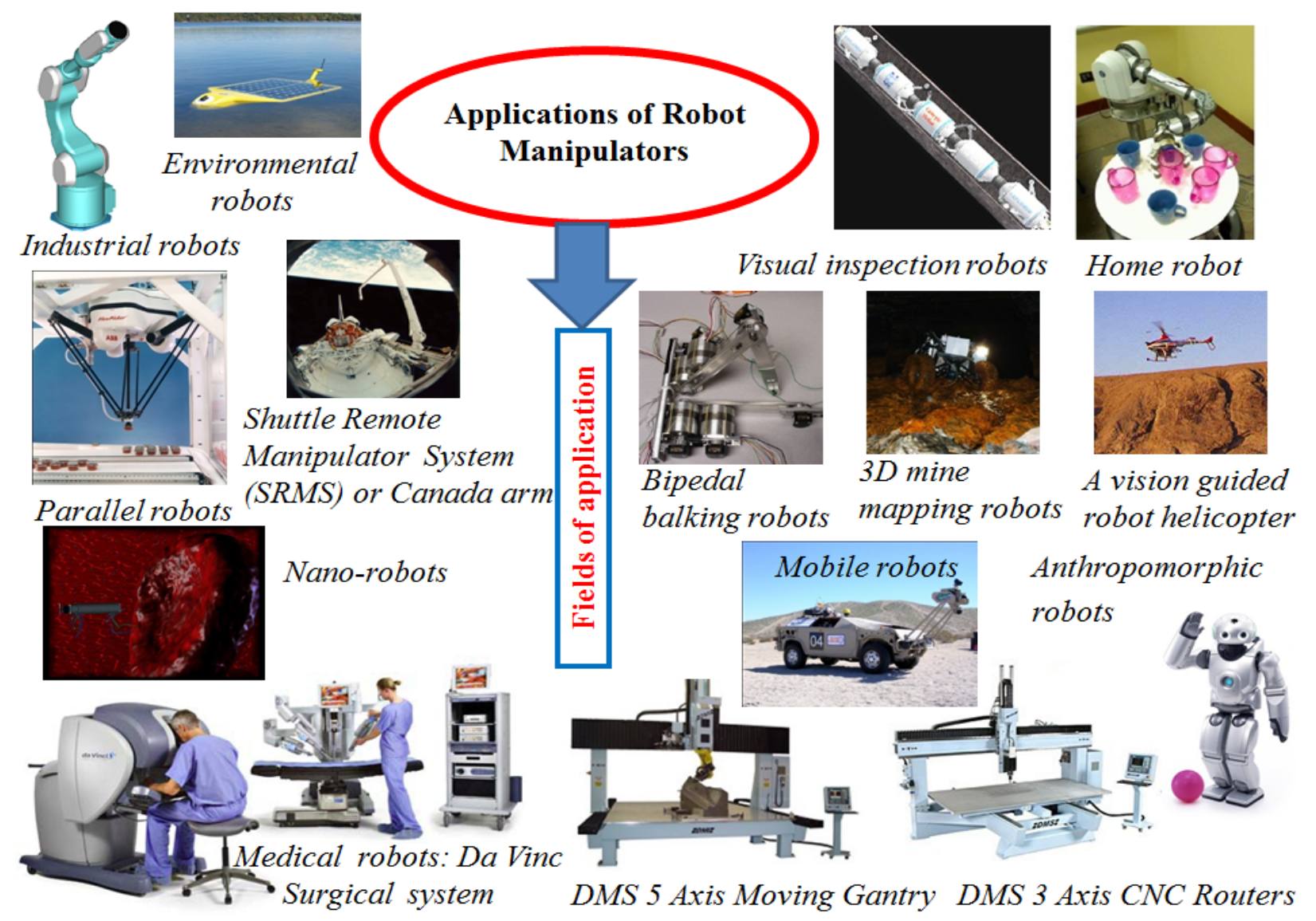

Figure 1: Applications of robot manipulators 
Today's manufacturing environment is dominated by market change and global competition. Manufacturing success and survival are characterized by low cost and high quality to meet market and customer demands. Automation, a key element of manufacturing systems, provides a comprehensive view of an integrated, fully engineered system. It represents the connection between mechanical, electrical, and manufacturing components. Robots, as essential parts of automated systems, are a great way to inspire students to learn about math, science, and technology. Robotics is a process that covers different subjects from mechanical and electrical areas, including design, modeling, sensors and signal conditioning, control systems, and actuator development. It is difficult to teach a well-balanced machinery class without favoring one discipline over the others, since most instructors are part of a mechanical or electrical engineering group. Because of its multidisciplinary nature, the study of robotics in the classroom can be a valuable tool for the practical, hands-on application of concepts across various engineering and science topics. Robotic applications are everywhere, in the Manufacturing Industry, Defense and Military Applications, Medicine and Health, Assistance to the Handicapped, Entertainment, Education, Safety, and much more. A wide spectrum of applications of robot manipulators is shown in Figure 1.

\section{Robotics, Mechatronics and Automation Curriculum at Mechanical Engineering Technology, Wayne State University, Detroit, Michigan}

The main role of the funding sought for this project, funded by Wayne State University's Intramural Fund Support, was to purchase a Robotics Education Training Package to develop additional courses that would use that equipment. The main objective of this project is to educate students in the area of emergent technology of machinery automation, which includes kinematics, dynamics, control, modeling, design, build, simulation, programming, and automation. The Robotics Education Training Package contains seven elements presented in Figure 2.
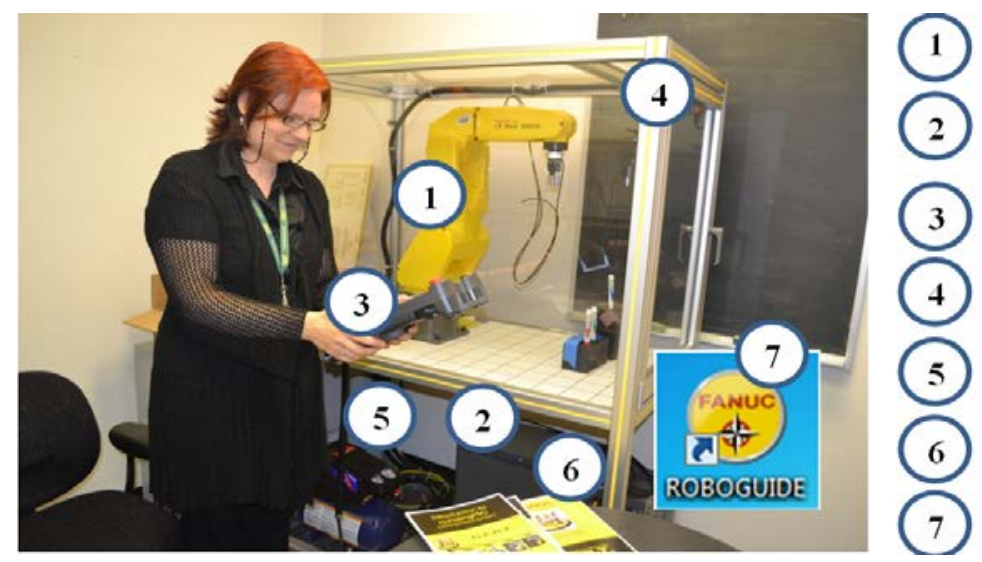

6-DOF Fanuc LR Mate 200ic Robot

R-30iA Mate Controller and

$\mathrm{R}$ Handling Tool Software

Teach Pendent

Mobile Training Safety Enclosure

Air Compressor

CERT Program

ROBOGUIDE Simulation software

Figure 2: Elements of the Education Training Package

The course offered at Wayne State University is a four credit-hours lecture/lab course at the senior level with five contact hours (two hours of lecture and three hours of laboratory) each week. Since the proposed course is a multidisciplinary one, it is then suitable for students from both engineering and engineering technology majors. The prerequisites for the proposed Robotics Education Training for Manufacturing Automation course is Computer -Aided Design \& Manufacturing, or Control Systems, or Industrial Robots Modeling and Simulation, or 
Kinematics and Dynamics of Machines. A new course named "Robotics Education Training for Manufacturing Automation” was developed in the Division of Engineering Technology (ET) at the College of Engineering. The main focus of this course was to assist students to apply the knowledge from the following courses: Computer - Aided Design \& Manufacturing, Control Systems, Industrial Robots Modeling and Simulation, Kinematics and Dynamics of Machines, Senior Project, Mechatronics, Microprocessor and Programmable Logic Controllers and Directed Study (Industrial Robots Dynamics and Control). The structure of the multidisciplinary approach for the robotics education is given in Figure 3.

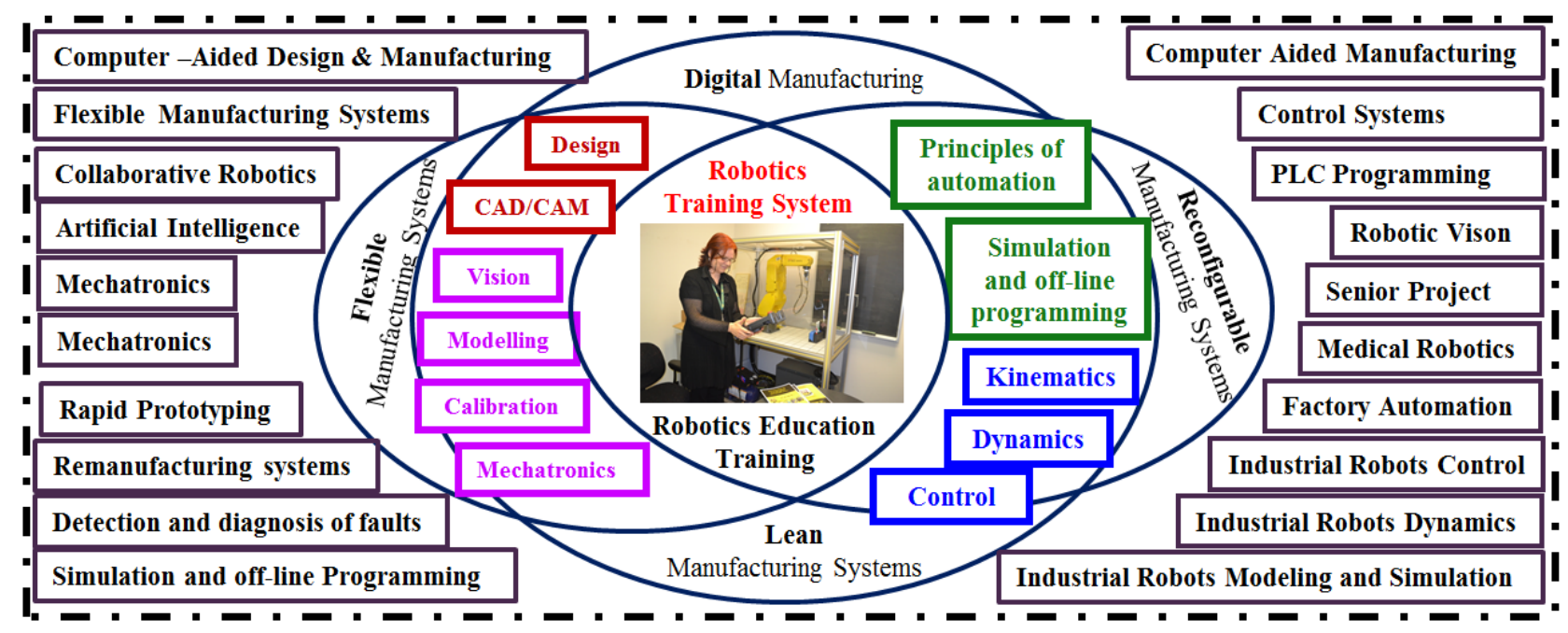

Figure 3: Multidisciplinary approach of using Education Training Package at Wayne State University

This course for the one-semester class includes four disciplines: (i) robotic applications in different manufacturing systems, (ii) basic industrial robotic theory (joints, links, D-H parameters, direct and inverse kinematics, direct and inverse dynamics (recursive methods), singularity problem (Jacobian matrix), and robot Workspace), (iii) safety procedure in robotics applications, and (iv) robotic simulation, and offline and online programming. The robotic lab, which is used for this course, includes the FANUC Robotics Education Training Cart and the full size industrial robot FANUC S430 iw, as shown in Figure 4.

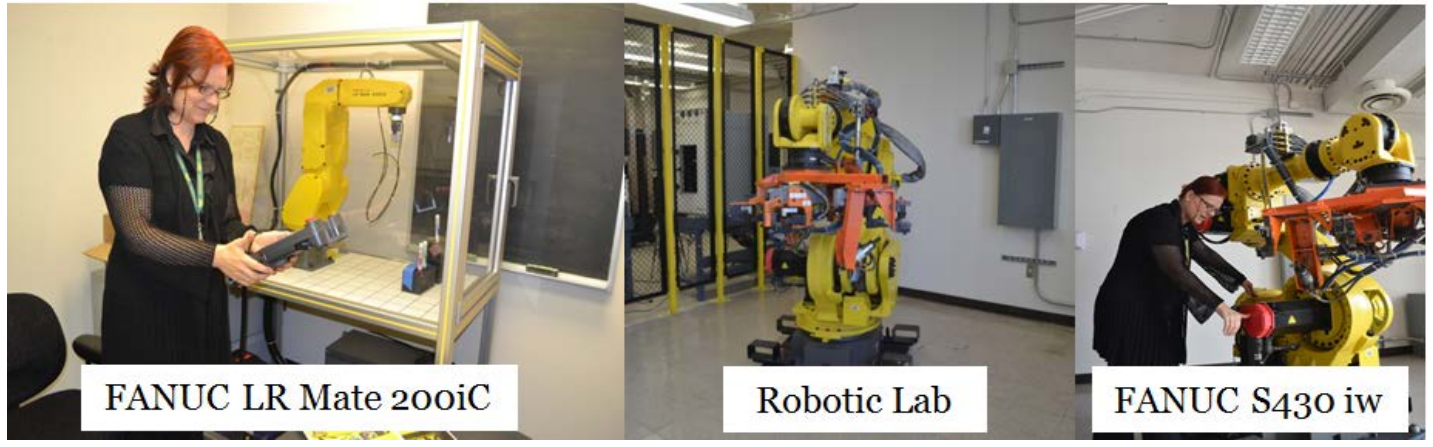

Figure 4: The robotic lab at the Engineering Technology department at Wayne State University 
In this course, students are getting a chance to explore robot kinematics, robot modeling, simulation, off-line programming, system integration for different applications, automation of manufacturing systems, and use different software packages by performing simple experiments. Students have the opportunity to apply the robotic theory using six axis industrial robots, and efficiently using these tools to solve existing industrial problems. This course unified different engineering disciplines to solve many important manufacturing automaton problems. As a final project, students are expected to model and simulate a work cell for the selected application and to perform the same with the physical robots in the lab. They will compare both outcomes for evaluation of the calculated results. Students submit a comprehensive engineering report to document all requirements. Experiments and projects are designed and implemented in a sequence that would allow the students to acquire a complete manufacturing automation experience. This included on-line and off-line robot programming (uploading and downloading programs between robots controllers and simulation software), robot integration (adding peripherals to a robot(s) to create a complete unit), evaluation of the robot kinematic models, and troubleshooting abilities. With the experience gained in the laboratory, students are able to know the design process, methods, and implementation issues involving different robotic systems. Together, these laboratory experiments support all these aspects and the multidisciplinary components of the manufacturing process automation.

The mean learning objectives in this course are focused on giving student teams an opportunity to: understand basic robotic theory used in the robotic system (direct kinematics, inverse kinematics, links, joints, coordinates systems, robot languages, online and offline programming) and learn how to program and maintain an R-J or higher controller with a standard application software package. It involves both classroom instruction and hands-on training. The assessment method used in this course includes regular tests and exams and industry based certification.

\section{Robotics, Automation and Mechatronics Curriculum at Mechanical Engineering Technology, Old Dominion University, Norfolk, Virginia}

The engineering Technology curriculum at Old Dominion University includes various courses that focus on the areas of robotics, mechatronics, and automation ${ }^{14}$. All students in the Mechanical Engineering Technology Program are required to take Automation and Controls and Automation and Controls Lab as a part of their core courses. The assembly line includes three industrial robots and one machine vision station, as shown in Figure 5.

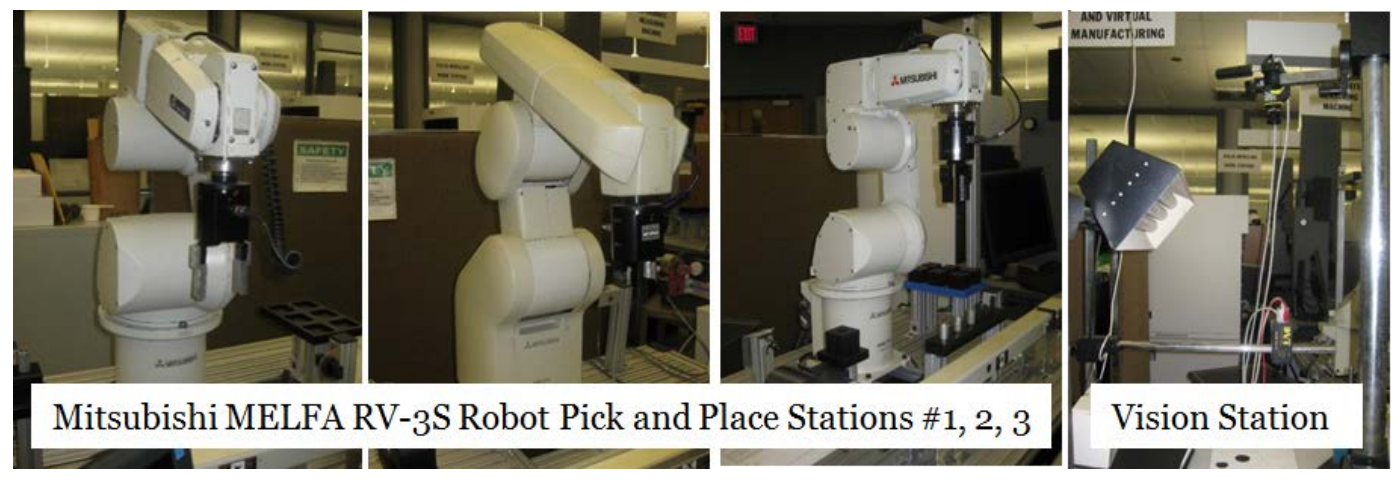

Figure 5: Industrial Robots in Automated Manufacturing Laboratory at Old Dominion University 
Furthermore, Mechanical Engineering Technology students ${ }^{14}$ are required to take three courses from the Electrical Engineering Technology program: Advanced Technical Analysis, Fundamentals of Electrical Technology, and Electrical Laboratory. In addition, they have various available senior elective courses in the area of advanced manufacturing, such as: Computer Numerical Control in Production, Introduction to Robotics, Advanced Manufacturing Processes, and Introduction to Mechatronics, Mechatronics Systems Design and Computer Integrated Manufacturing. Moreover, students in this program can take a course from Electrical Engineering Technology as their senior elective: Electrical Power and Machinery. Labs used for these courses are Automated Manufacturing Laboratory, Automation and Controls Laboratory, Computer Aided Drafting \& Design Laboratory, Basic Electronics Laboratory, and Power Systems Laboratory. The Introduction to Robotics course at Old Dominion University is an introductory course in robotics dealing with the history and development of robots, mechanical components and control systems, actuators, robot programming and utilization. Included are laboratory, experiments in robot motion and programming. ${ }^{15}$ The Introduction to Robotics lab has training sections offered on three Mitsubishi robots and two machine vision systems, as shown in Figure 5. Two different courses in the area of Mechatronics were developed in the school year 2012-13 to compliment the robotics course: Introduction to Mechatronics and Mechatronics Systems Design. Introduction to Mechatronics is the study of the mechatronics concepts and their application on actual problems encountered in engineering practice. This course includes the basics of electromechanical systems, electrical circuits, solid-state devices, digital circuits and motors, all of which are fundamental to understanding mechatronic systems, whereas the Mechatronic System Design course is the study of integrated modeling and optimal design of a physical system, which includes sensors, actuators, electronic components, and its embedded digital control system. It includes simultaneous optimal design practice with respect to the realization of the design specifications related to different engineering domains ${ }^{15 .}$

\section{Robotics, Automation and Mechatronics Curriculum at Mechanical Engineering Technology, Purdue University, West Lafayette, Indiana}

The Mechanical Engineering Technology program of Engineering Technology at Purdue University has concentrations in: 1) Automation and Systems Integration; 2) Mechatronics; and 3) Robotics. These new areas of concentrations are available for students who are enrolled from fall 2014 and on. Graduates of the mechatronics concentration will be able to apply embedded controllers to mechanical systems, automation and systems integration, which focuses on design and manufacturing process related skills, and the area of specializations in robotics learn how to implement robotic solutions in industrial settings ${ }^{16-18}$. Various manufacturing courses are offered in a hands-on environment at the automated manufacturing laboratories, such as the Automated Manufacturing Center, as shown in Figure 6. One of these courses is named Applications of Automation Manufacturing. In this course students learn a basic introduction to automation applications in manufacturing and the impact of computer-based systems on a manufacturing company. Course coverage includes practices and the various issues related to the application of computer-integrated manufacturing. There is emphasis placed on CAD, CAM, CNC, robotics, industrial control elements, PLCs, and computer-based process controls. 


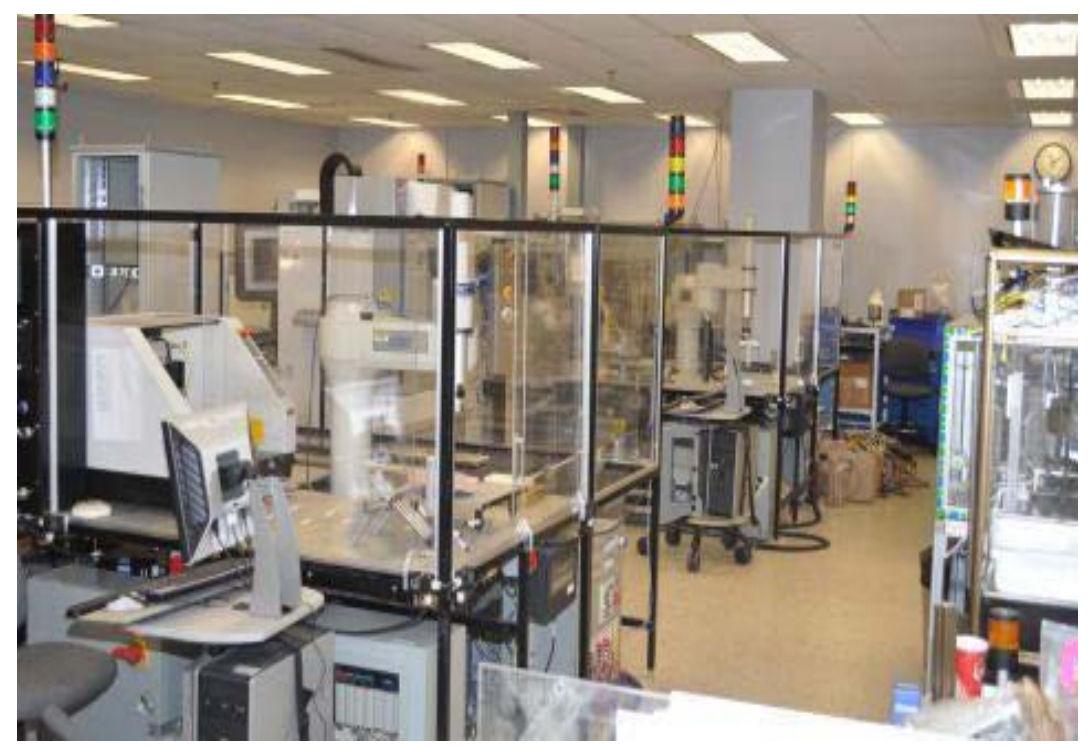

Figure 6: Automated Manufacturing Center at Engineering Technology, Purdue University, West Lafayette, Indiana ${ }^{19}$

\section{Advanced Manufacturing Training Implementation}

Wayne State University: Robotics, automation, and mechatronics curriculum at Mechanical Engineering Technology, Wayne State University has recently developed three new courses since the 2011-2012 school year: 1) Robotics Education Training for Manufacturing Automation; 2) Industrial Robots Modeling and Simulation; and 3) Industrial Robots Dynamics and Control. The Robotics Education Training for Manufacturing Automation course has been offered two times so far. Currently 30 students are registered. Industrial Robots Modeling and Simulation has been taught four times. Currently 16 students are registered. Industrial Robots Dynamics and Control is currently in the development stage and it is going to be offered in the Fall 2015.The advanced related material is published in ${ }^{23}$ material. As a result of these courses, so far 15 students completed the senior projects, three students completed the Master Projects, and many more students are currently working on the undergraduate and graduate robotic research projects. The outcomes of their research are published in ${ }^{20-22}$. In the summer 2015 at the Wayne State University, 30 Brazilian students will be working on different robotic projects.

Old Dominion University: The robotics, automation and mechatronics curriculum at Mechanical Engineering Technology, Old Dominion University has recently developed two new courses since the 2012-2013 school year ${ }^{24-30}$. The first course, Introduction to Mechatronics, has been offered three times so far, with an average of 20 students per semester. The second new course, Mechatronics Systems Design, is currently being offered for the third time with an average of 30 students per semester. As a result, various students who completed the courses had their senior projects in the area of design of mechatronics (electro-mechanical) systems, which are controlled by Arduino controller - 11 student teams with 28 MET undergraduate students. Students were able to program their devices by merging separate open source codes for different actuators, sensors and LED diodes. This is an especially important experience for MET students because they do not have a programming course in their curriculum. They learn Matlab in Advanced Technical Analysis, so they were able to understand C code, which is used for Arduino because it resembles a Matlab coding techniques. In two of these projects - IEEE 
SouteastCon Hardware competition in 2012-13 and 2013-14, MET students participated with students from Electrical and Computer Engineering on the design and manufacture of robotics cars. In 2014-15 year, MET students participated in the ASME Robot for Relief competition with students from the Mechanical and Aerospace departments.

Purdue University: There is a clear understanding that Advanced Manufacturing is a matter of fundamental importance to the economic strength and national security of the United States. Traditionally, educational programs related to Advanced Manufacturing at Purdue University have been given great attention from local and nationwide businesses and industries ${ }^{31}$. Since Purdue University has about 10 local campuses, it is necessary to say the College of Technology is place in the three-year-old Advanced Manufacturing Center of Excellence, which is located in Columbus, Indiana. Center for Advanced Manufacturing exists for more than 10 years on main campus, in West Lafayette, Indiana, as part of Discovery Park. Exclusive features of the Center of Advanced Manufacturing in Columbus, Indiana include unique CNC equipment and an environmentally controlled metrology laboratory, which are used for multiple educational and research projects. In the recent publication ${ }^{32}$, this center was described as "a minds- and hands-on experience for students and researchers." This center brings a unique blend of education and experience into classroom discussions, benefiting all.

\section{Student Perceptions}

Wayne State University: Some of the students who took these newly developed courses at Wayne State commented that they enrolled for these courses even if the course was not a requirement for their major. They were motivated to learn and find applications in their field of study and enjoyed these very practical courses. Another student mentioned that although the material was difficult for him as an undergraduate student, he was thankful that they were given a chance to practice mathematical models and work on related lab activities, which would help him understand topics such as kinematics, dynamics and matrices. Others commented that they had learned a great deal, both mathematically and about robots, and that the math review helped them to better understand more complex topics.

Old Dominion University: Perceptions of some students who took Introduction to Mechatronics and Mechatronic System Design included students who would not normally participate were engaged by infusing the classroom with challenging projects and hands on learning (this class had fifteen labs which were based on Arduino sensor kit); the class was interesting and fun (this class had a SumoBot competition at the end of the course); and students were introduced to a completely new facet of engineering with diverse curriculum.

Purdue University: Since the MET student population is a mix of traditional college-aged students, who recently have graduated from high school, and nontraditional students already in the workplace, their perceptions of introduced in-class material might vary largely. Team work in robotics courses is a traditional approach, but it might create difficulties in grading and assessment of students. The other new approach that has recently been presented to students (and which has broad spectrum of "likes" and "do not likes" from the students) is assessing not "material that they learn," but the competencies that were developed completing the course. 


\section{Manufacturing Program Goals Assessment}

There are various ways to evaluate the attainment of student learning outcomes. Tests, quizzes and exams as quantitative and qualitative measures, designed with integrated questions related to the specific ABET curriculum student outcomes are one way to approach the assessment. Another way is to offer students the option to earn industry acknowledged certifications as a form of direct measure in which student performance of on hands robot control is evaluated (ABET General Criteria - Criterion 1 - Students). In addition, ABET’s Criterion 5 Curriculum, more specifically: “c. Develop student competency in the use of equipment and tools common to the discipline” is measured with this certification. Wayne State University is offering students who are enrolled in industrial robotics class to earn an industry certificate. To qualify for this kind of examination they are required to complete 40 hours of training on industrial robots. This might be challenging to schedule if there are many students in the session or even not feasible for universities with large number of students who are enrolled in some kind of distance learning program and taking this class off-site through Webex or satellite. In mechatronics courses, students are required to complete 15 labs with an Arduino controller. For their final project, they are required to assemble and program a robotic kit, a SumoBot in the introductory course and an Arduino controlled robot in the second course, as shown in Figure 7. The main purpose of SumoBot assembly and programming is to recreate an excitement related to the robotic competition in the class and in the Arduino based fire alarm robot to challenge students to combine various circuits and control programs for actuators on a specific problem.
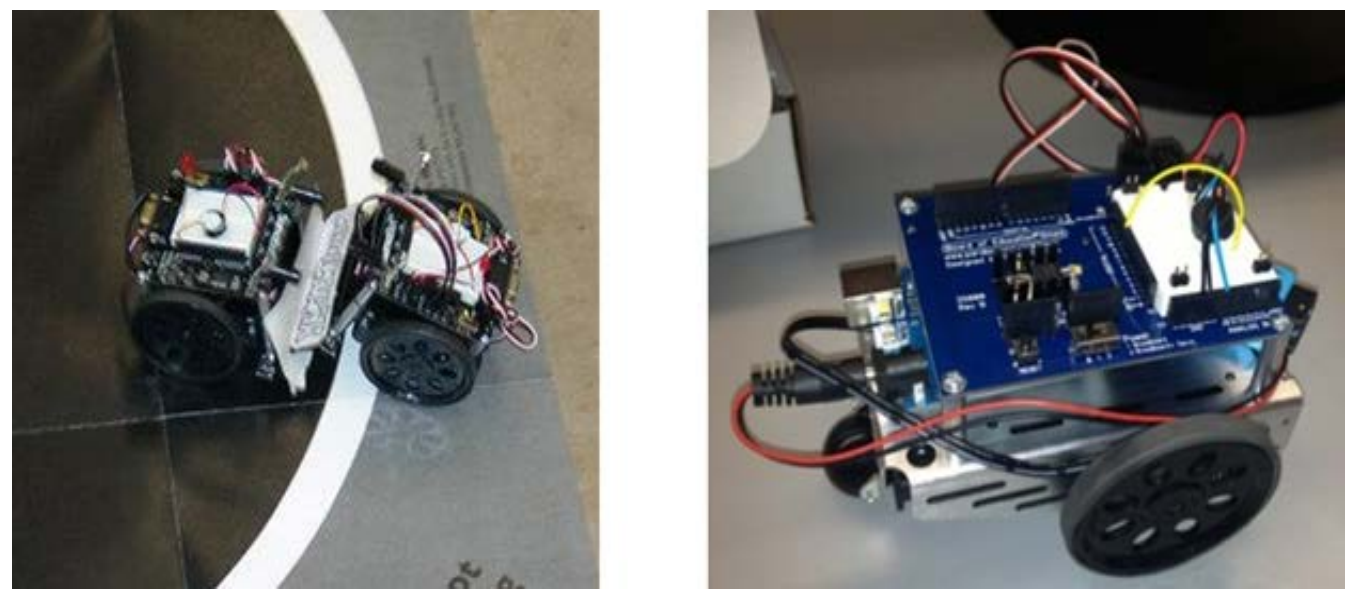

Figure 7. SumoBot (on the left) and Arduino controlled fire alarm robot (right)

Students in the Mechatronics System Design course were given the final project to write a report of the ideation phase of design of one robotic device for one student hardware competition. This assignment was writing intensive and required them to use appropriate citations, to use figures, and all necessary technical documentation that they developed during the ideation design phase in their team. In this way, another ABET outcome was integrated into the course design, the outcome: $\mathrm{k}$ ) the ability to apply written, oral, and graphical communication in both technical and non-technical environments; and an ability to identify and use appropriate technical literature. They were asked to present their ideas in front of the class, they formed teams and defended their design ideas in front of the class, in their final presentations, and in the final report. 


\section{Conclusion}

Employers in the advanced manufacturing sector expect that any type of engineer has basic knowledge in robotics and automation. Because of that, a very large number of students are interested in taking automation, manufacturing, and robotics related courses. They are from different engineering departments and with different backgrounds, which makes it for the instructor to successfully complete the course. Using the simulation tools to teach basic and advanced topics in robotics lead to excellent results. The unique simulation tools were developed to visualize the kinematic and dynamic equations in 3D space. Students use this knowledge to solve real industrial problems. They deliver very unique results, which can be used for publications. Automation and industrial robotics are the key element in many engineering disciplines. This includes students in Mechanical Engineering Technology, Electrical/Electronic Engineering Technology and Manufacturing/Industrial Engineering Technology. Although there are various universities offering a wide range of courses related to the robotics education, not each one of these efforts is focused on this specific application; the area of manufacturing automation. Courses related to this area are often offered in programs related to Mechanical Engineering, Electrical Engineering, Computer Engineering, and Computer Science. Students in engineering programs have different mathematics requirements than the students enrolled in Engineering Technology programs. Hence, Engineering Technology students cannot enroll in courses that require extensive knowledge of Calculus and programming. On the other side, Engineering Technology students can very often be employed by manufacturing companies. Therefore, it is very important to develop such opportunities for them so that they can integrate faster into a workplace that has these advanced manufacturing systems. Therefore, these new

additions to the robotics, automation, and mechatronics curriculum at Mechanical Engineering Technology programs, at the three universities presented in this paper, focused on development of student competency in the use of equipment and tools common to the discipline, which is especially important for students who prefer learning by doing learning method (tactile or kinesthetic learners). In addition, midterm project proposals and final project reports and presentations had embedded students learning outcomes in the areas of written, oral, and graphical communication in both technical and non-technical environments. 


\section{References}

[1] IFR. (2011). Positive Impact of Industrial Robots on Employment International Foundation of Robotics. London, U. K.: Metra Martech.

[2] Anderson, A. (2011). Report to the President on Ensuring American Leadership in Advanced Manufacturing. Executive Office of the President.

[3] Rawat, K. S., \& Massiha, G. H. (2004, April 26-May 1, 2004). A hands-on laboratory based approach to undergraduate robotics education. Proceedings of the ICRA '04, 2004 IEEE International Conference on Robotics and Automation.

[4] Nagai, K. (2001). Learning while doing: practical robotics education. Robotics \& Automation Magazine, IEEE, 8(2), 39-43.

[5] Dessouky, M. M., Bailey, D. E., Verma, S., Adiga, S., Bekey, G. A., \& Kazlauskas, E. J. (1998), A Virtual Factory Teaching System in Support of Manufacturing Education. Journal of Engineering Education, 87(4), 459-467.

[6] Radharamanan, R, \& Jenkins, H. E. (2008), Laboratory learning modules on CAD/CAM and robotics in engineering education. International Journal of Innovative Computing, Information and Control, 4(2), 433443.

[7] Bischoff, R., Kurth, J., Schreiber, G.R, Koeppe, R. Albu-Schäffer, A., Beyer, A., Grunwald, G. (2010), The KUKA-DLR Lightweight Robot arm-a new reference platform for robotics research and manufacturing. Paper presented at the Robotics (ISR), 2010 41st international symposium on and 2010 6th German conference on robotics (ROBOTIK).

[8] Manseur, R. (2005), Virtual reality in science and engineering education. Paper presented at the Frontiers in Education, 2005. FIE'05. Proceedings 35th Annual Conference.

[9] Arshad, H., Jamal, J., Sahran, S. (2010), Teaching robot kinematic in a virtual environment. Paper presented at the Proceedings of the world congress on engineering and computer science.

[10] Candelas H., Francisco, A., Jara B., Carlos A., Torres Medina, F. (2006), Flexible virtual and remote laboratory for teaching Robotics, Retrieved on March 6, 2015 from: http://hdl.handle.net/10045/2906

[11] Moore, P. R., Pu, J., Ng, H.C., Wong, C.B., Chong, S.K., Chen, X., Lundgren, J.O. (2003). Virtual engineering: an integrated approach to agile manufacturing machinery design and control. Mechatronics, 13(10), 1105-1121.

[12] Hirose, S. (2001), Creative education at Tokyo Institute of Technology, International Journal of Engineering Education, 17(6), 512-517.

[13] Levin, I., Kolberg, E., Reich, Y. (2004). Robot control teaching with a state machine-based design method. International Journal of Engineering Education, 20(2), 234-243.

[14] Old Dominion University (2015), Mechanical Engineering Technology Advising Sheet, Available: http://www.eng.odu.edu/et/pdf/MET\%20Advising\%20Sheet\%202012-2013.pdf

[15] Old Dominion University (2015), Undergraduate Course Catalog. Available: http://catalog.odu.edu/pdf/2014-15-undergraduate.pdf

[16] Purdue University (2015), Automation and Systems Integration Concentration, School of Engineering and Technology, Purdue University, West Lafayette, IN,, Retrieved on January 31, 2015 from: https://tech.purdue.edu/degrees/automation-and-systems-integration

[17] Purdue University (2015), Mechatronics Concentration, Engineering Technology, Purdue University, West Lafayette, IN, Retrieved on January 31, 2015 from: https:/tech.purdue.edu/degrees/mechatronics

[18] Purdue University (2015), Robotics Concentration, Engineering Technology, Purdue University, West Lafayette, IN, Retrieved on January 31, 2015 from: https://tech.purdue.edu/degrees/robotics

[19] Purdue University (2015), Automated Manufacturing Center, Engineering Technology, Purdue University, West Lafayette, IN, Retrieved on January 31, 2015 from: https://tech.universityC.edu/facilities/automatedmanufacturing-center

[20] Arachchige, P. W. , Abderrahmane, M. S. , Djuric, A. M. (2014), "Modeling and Validation of Rapid Prototyping Related Available Workspace”, SAE International Journal of Materials and Manufacturing 7(2):291-299, 2014.

[21] Abderrahmane, M. S. , Djuric, A. M., Chen, W., Yeh, C. P. (2014), "Study and Validation of Singularities for a Fanuc LR Mate 200iC Robot”, 2014 IEEE, International Conference on Electro/Information Technology, pp. 432-437. 
[22] Arachchige, P. W., Abderrahmane, M. S., Faculty Advisor: Dr. A .M. Djuric, (2013), "Design of Reconfigurable Joints for the Advance Robotic Systems", National Conference on Undergraduate Research (NCUR) 2013, University of Wisconsin La Crosse, WI, April 11 - 13, 2013.

[23] Djuric, A. M., Al Saidi, R., ElMaraghy, W. H. (2012), "Dynamics Solution of n-DOF Global Machinery Model“, Robotics and Computer-Integrated Manufacturing, Vol. 28, Issue 1, pp. 621-630.

[24] Jovanovic, V., Verma, A., Tomovic, M. M. (2013), "Development of Courses in Mechatronics and Mechatronic System Design within the Mechanical Engineering Technology Program”, The 11th Latin American and Caribbean Conference for Engineering and Technology - LACCEI 2013, "Innovation in Engineering, Technology and Education for Competitiveness and Prosperity”, Cancun, Mexico, August 1416, 2013.

[25] Jovanovic, V., Verma, A., Tomovic, M. M. (2013), “Developing an Option in Mechatronics System Design within the Mechanical Engineering Technology Program”, 2013 International Forum on Systems and Mechatronics, Guilin, China, July 22-25, 2013.[24] Ostojic, G., Jovanovic, V., Kozak, D., Ivandic, Z., Stankovski, S. "Mechatronic Education at Faculty of Technical Sciences Novi Sad”, Technical Gazette (Tehnicki vjesnik), Vol. 22, Issue 3, June 2015.

[26] Michaeli, J. G., Jovanovic, V., Popescu, O., Djuric, A., Yaprak, E. (2014), “An Initial Look at Roboticsbased Initiatives to Engage Girls in Engineering“, Technology Interface International Journal (TIIJ), Spring/Summer 2014, Vol. 14, No. 2, 2014.

[27] Senk, I., Ostojic, G., Jovanovic, V., Tarjan, L., Stankovski, S. (2012), “Experiences in Developing Labs for a Supervisory Control and Data Acquisition Course for Undergraduate Mechatronics Education”, Computer Applications in Engineering Education, DOI: 10.1002/cae.21578., 2012.

[28] Stankovski, S., Ostojic, G., Tarjan, L, Senk, I, Jovanovic, V. (2010), "Development and Implementation of Didactic Sets in Mechatronic and Industrial Engineering Courses”, International Journal of Engineering Education, Vol. 26, Issue 1, pp. 2-8, 2010.

[29] Jovanovic, V., Michaeli, J. G., Popescu, O, Moustafa, M. R., Tomovic, M., Verma, A., Lin, C. (2014), "Implementing Mechatronics Design Methodology in Mechanical Engineering Technology Senior Design Projects at the Old Dominion University” ASEE National Conference 2014, June 15-18, Indianapolis, IN, 2014.

[30] DeAgostino, T., Jovanovic, V., Thomas, M. B. (2014), “Simulating Real World Work Experience in Engineering Capstone Courses” ASEE National Conference 2014, Session: College Industry Partnership, June 16-18, Indianapolis, IN, 2014.

[31] Purdue University (2015), GE to collaborate on advanced manufacturing to enable faster, efficient brilliant factories. Retrieved on March 10, 2015 from https://purdue.edu/newsroom/purdue-ge-collaborateadvanced-manufacturing-enable-faster-efficient-brilliant-factories

[32] Purdue University (2015), Advanced Manufacturing Center of Excellence promotes collaboration. Retrieved on March 10, 2015 from https://purdue.edu/newsroom/advanced-manufacturing-center-ofexcellence-promotes-collaboration 